\title{
Deposit Mechanism Design and Corresponding Decision Strategy considering Uncertainty of Customer Behaviour
}

\author{
Qingshan Xu ${ }^{D},{ }^{1}$ Mengjia Liu ${ }^{D},{ }^{1}$ Yu Huang, ${ }^{1}$ Hong Sun, ${ }^{2}$ and Xinjia Li ${ }^{2}$ \\ ${ }^{1}$ School of Electrical Engineering, Southeast University, Nanjing 210096, China \\ ${ }^{2}$ Jiangsu Frontier Electric Technologies Co., Ltd., Nanjing 211102, China \\ Correspondence should be addressed to Mengjia Liu; 220162210@seu.edu.cn
}

Received 20 June 2018; Accepted 16 August 2018; Published 30 September 2018

Academic Editor: Gaetano Zizzo

Copyright (c) 2018 Qingshan Xu et al. This is an open access article distributed under the Creative Commons Attribution License, which permits unrestricted use, distribution, and reproduction in any medium, provided the original work is properly cited.

\begin{abstract}
Demand response (DR) has received great concern since the significant growth in electricity consumption and peak-valley difference were witnessed recently. Based on the theory of customer psychology, an uncertainty model of customer behaviour is proposed. By converting electric power to deposit points, a novel deposit mechanism is designed in this paper, which can better deal with the special situations in China. Compared with traditional mechanism, the proposed deposit mechanism is capable of improving acceptability of DR methods in China and achieving greater mobilization of customer motivation for its more understandable rules and higher participation compensations. Furthermore, a decision strategy considering benefits of both the power company and the subscribed customers is proposed based on the uncertainty model of customer behaviour and the proposed deposit mechanism, which aims at achieving win-win situations and greater mobilization of customer motivation. The uncertainties in decision strategy are quantified by the uniform design sampling (UDS) method which is more efficient and computationally accurate than traditional Monte Carlo simulation. With the electricity data of Nanjing City, China, the superiority of proposed deposit mechanism and decision strategy are verified by numerical simulations.
\end{abstract}

\section{Introduction}

In face of increasingly severe global power supply shortages, the bilateral interaction of information or power between suppliers and buyers is emphasized by encouraging customers to optimize their consumption behaviour in a more reasonable way [1-4]. Therefore, demand response (DR) is widely implemented to motivate customers to participate in power system operation, so as to defer the investment of new power plants and transmission or distribution networks [5]. Accordingly, depending on how DR responses, they can be divided into price-based DR and incentive-based DR. Customer's consumption behaviour is changed based on electricity prices in the first category and in response to incentive measures within a predetermined time in the second category $[6,7]$.

Nevertheless, price-based DR is more applicable to a competitive power market and is with greater uncertainty as well as less schedulable potential. Hence, incentive-based DR is more suitable for dealing with capacity shortage events due to its striking responsiveness and stability [8]. The works carried out nowadays include design and operation of demand response mechanism $[9,10]$, modelling/controlling of demand side resources assisting in integrating renewable energy [11, 12], and so on [13]. However, the reformation of electricity market and demand side management (DSM) has just started in China, leading to the lack of mature electricity market and low customer participations. The special situations make the existing DR methods in other countries difficult to be effectively applied to DSM in China. In order to improve customers' participation motivation, the idea of deposit mechanism is proposed considering the actual nation situations of China based on the theory of fundamental saving [14]. The demand side resources are regarded as special commodities with appreciated function that can be returned to customers in the future under deposit mechanism. Compared with traditional mechanism, the proposed deposit mechanism is capable of easing tension during peak periods and increasing load level during valley periods, which is beneficial to reduce peak-valley differences 
of the power system [15]. The actual operating process as well as reward/punishment rules of deposit mechanism also requires deep research. Hence, how to design the operating rules of deposit mechanism by emulating the deposit and withdrawal rules of funds in banks and establish an appropriate decision strategy based on deposit mechanism of capacity shortage events have become an urgent and important issue for the realization from theory to application of deposit mechanism and promoting the development of demand side management (DSM) in China.

It is widely acknowledged that changes of customer consumption in the process of demand response can be rather stochastic and unpredictable $[16,17]$. The uncertainty of customer behaviour has a significant influence on decision strategy of capacity shortage events and a variety of works have been done already. For instance, the transactions between different operating modes with uncertainties submitting to some certain distributions are imposed in $[18,19]$ to describe the actual consumption patterns of customers, which fails to precisely reflect the situation of load reduction. Moreover, a cross-elasticity model between demand side participation and price/incentive measures is established in $[20,21]$ with universality under different conditions. This method takes the influence of penalty into consideration but neglects the relationship between incentive level and customer behaviour. Thus, the uncertainty model of considering customer psychology is introduced in this paper to reveal the relationship between incentive level and load reduction as well as its uncertainty.

In terms of uncertainty quantification methods, there exist three main categories: simulation method, approximation method, and analytical method. Monte Carlo simulation is widely utilized due to its simplicity and applicability as a typical simulation method [22]. However, it is rather time-consuming. Approximation methods such as point estimation method $[23,24]$ and analytical methods such as cumulant method [25] can reduce computational time effectively, but are both with limitations for their complicated solutions and theoretical model architectures. As a result, researchers turn to ameliorate sampling measurements with the purpose of simplifying models or optimizing sample size, such as the uniform design sampling (UDS) method [26, 27].

Based on existing studies, operating rules of deposit mechanism and a novel corresponding decision strategy considering total benefits of both the power company and the subscribed customers are proposed in this paper. In order to realize the storage and value-added function under deposit mechanism, a deposit point method is proposed and applied into mechanism design, in which way the electric power can be converted into deposit points operating in a similar way of deposit/withdrawal process of bank funds. Based on the uncertainty model of customer behaviour considering customer psychology proposed in this paper, a decision strategy is also proposed to solve the optimal incentive level under capacity shortage event considering total benefits of both the power company and the subscribed customers, aiming at a win-win situation to achieve greater mobilization of customer motivation. The uncertainties in decision strategy are quantified by the uniform design sampling (UDS) method

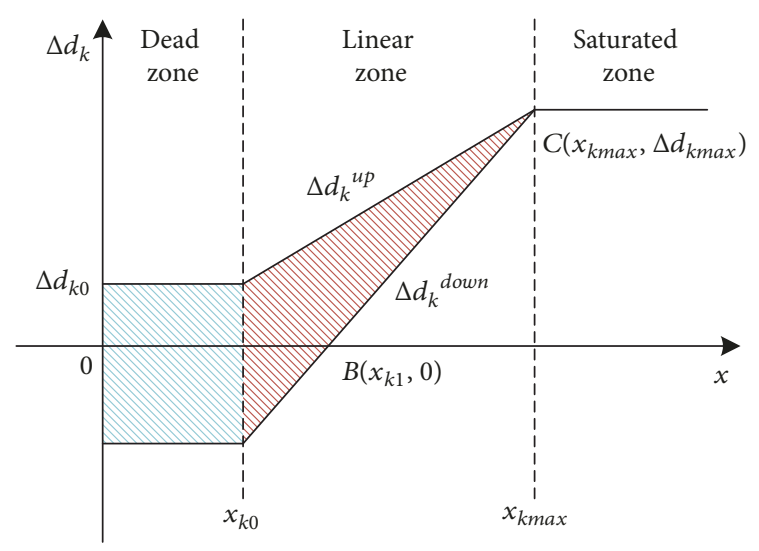

FIGURE 1: The curve of customer behaviour considering uncertainty.

to improve the sampling efficiency, computational accuracy, and error stability.

The rest of this paper is organized as follows. Section 2 proposes the uncertainty model of customer behaviour considering customer psychology. The design of deposit mechanism is explained in detail in Section 3. Then, the decision strategy considering uncertainty as well as the corresponding uncertainty quantification method (uniform design sampling method) is proposed in Section 4. After that, results of case studies are presented in Section 5. Finally, concluding remarks are drawn in Section 6.

\section{Uncertainty Model of Customer Behaviour}

It is acknowledged that loads are shed voluntarily by customers according to contractual contents during peak periods or emergency situations after receiving the notification from the power company when classified as incentive-based DR [28]. However, customer behavior is rather unpredictable but has a significant influence on the results of capacity shortage events. Hence, how to establish a model that can accurately estimate customer behavior under deposit mechanism becomes a key point. In this section, an uncertainty model considering customer psychology is introduced for estimation of actual load reduction of customer. The main idea is to associate incentive level with actual load reduction as well as its uncertainty, in which way the actual customer behavior can be simulated by interval parameters so as to improve the applicability of the model.

Incentive level not only affects the amount of load reduction, but also affects its uncertainty, thus determining the actual situation of customer response behavior. The higher the incentive level is, the stronger customers' willingness of load shedding and less uncertainty can be accounted for, due to the driving effects of interests.

The curve of customer behavior considering uncertainty based on customer psychology is shown in Figure 1. The horizontal axis represents incentive level $x$, while the vertical axis represents the amount of load reduction $\Delta d$.

Assume that $x_{k 0}$ represents initial incentive level for customer $k$ where the voluntarily load reduction starts; $x_{k 1}$ 
represents critical incentive level where customer $k$ will no longer increase power consumption despite uncertainty; $x_{k 2}$ represents saturated incentive level where load reduction achieves the maximum value. $\Delta d_{k}^{u p}, \Delta d_{k}^{d o w n}$ are, respectively, the upper and lower limits of load reduction. At incentive level $x_{k}$, the actual load reduction $\Delta d_{k}\left(x_{k}\right)$ is a random variable, which is distributed normally within the interval $\left[\Delta d_{k}^{u p}\left(x_{k}\right), \Delta d_{k}^{\text {down }}\left(x_{k}\right)\right]$.

The curve is divided into three zones by the range of incentive levels: dead zone, linear zone, and saturated zone. In dead zone, the incentive level is too low to attract any customer where normal consumption patterns of customers stay the same with the existing of behavior uncertainty. In linear zone, interest-driven, there is a linear relationship between maximum/minimum load variation and incentive level, with a gradually decreasing trend of uncertainty. In saturated zone, load reduction remains unchanged and the uncertainty is rather negligible.

\section{Deposit Mechanism Design}

The work of demand side management (DSM) has just started in China recently, resulting in low acceptability and participation of demand response (DR) methods [14]. The successful research and experience in America and European markets cannot be directly applied to China, as the incomplete electricity market in China suffers much more factors which weaken the effectiveness of traditional methods. Aiming to adapt to the situations in China, a novel deposit mechanism is proposed based on the theory of fundamental saving [29]. The proposed method can improve customers' acceptance by emulating the operating rules of bank funds and achieve greater mobilization of customer motivation by increasing total benefits of subscribed customers, especially industry load customers with significant schedulable potential. In this way, the effectiveness of DR can be improved in China. Considering the real-time characteristics of electric power and the difficulty of building a large-scale power resource base, a deposit point method is proposed and applied into deposit mechanism design for realizing the storage, valueadded function of deposit points converted from electric power, which is analogous to the deposit and withdrawal process of bank funds. Contractual contents, especially the reward and punishment rules of deposit mechanism management, are also explained in detail to evaluate the effectiveness of customer's response for further compensation or penalties.

3.1. The Principle of Deposit Mechanism. Deposit mechanism is implemented by emulating the operation rules of funds where demand side resources are regarded as special commodities with saving and value-added functions. With the proposed mechanism, the low acceptability and participation of demand response (DR) methods in China can be improved for more understandable rules and higher participation compensations. Besides, smaller peak-valley differences of the power system can be achieved as well because the proposed deposit mechanism can not only ease tension during peak periods, but also promote electricity usage during valley periods.

According to the theory of fundamental saving, funds saved by customers are continuously increasing in their bank accounts because of interest until customers make withdrawals after a fixed period of time [29]. Similarly, the actual load reduction and incentive level are, respectively, regarded as principle and interest (appreciated rate) under deposit mechanism. Customers' load shedding during peak periods is analogous to deposit behavior while the acquirement of appreciated load for free during valley periods is analogous to withdrawal behavior after the storage time $N$.

However, due to the real-time characteristics of electric power supply and consumption, a large-scale power resource base functioning as the bank account is necessary for timely consumption and output of electric power, but rather difficult to implement. Hence, a deposit point method is put forward to solve this problem. Assume that the actual load reduction of customer can be converted into deposit points according to certain criteria, which can be stored into the deposit account created for each customer. The initial point in each deposit account is 0 and points are accumulated or deducted according to specific reward and punishment rules until they are withdrawn by customers to act as the proof of compensation. In this way, there is no need to establish a power resource base and the final points can be applied to evaluate the effectiveness of customer's response.

The principle of deposit point method for each customer is briefly shown in Figure 2. It is noted that each customer owns a deposit account, just like his/her bank account.

Deposit mechanism is implemented through bilateral contracts previously signed between the power company and the customer. Contents of bilateral contracts should clearly indicate the operating rules of deposit mechanism, including advanced notification time, load interruption requirements, storage time, reward, and punishment rules of deposit mechanism management, which can be explained as follows:

(1) Advanced notification time is generally set as $30 \mathrm{~min}$ to $2 \mathrm{~h}$ according to settings of contractual contents of traditional mechanism [30,31].

(2) Load interruption requirements include the response time, interruption duration, and the contractual amount of load reduction.

(3) Storage time is the time period when customers are unable to obtain appreciated electric power or pay extra money for punishment. The longer storage time $\mathrm{N}$ is, the greater effect of value-added function can be.

(4) Reward and punishment rules of deposit mechanism management are detailed in the following section "Reward and Punishment Rules".

Due to the special operating rules of deposit mechanism, it is capable of reducing peak load and promoting the level of electric power consumption during valley periods at the same time, thus making a greater contribution for the reduction of peak-valley difference compared with traditional mechanism. In addition, industry load customers are selected as the main focus of deposit mechanism because of their strong flexibility and great controllability, which account for a large proportion of total electricity customers. They can 


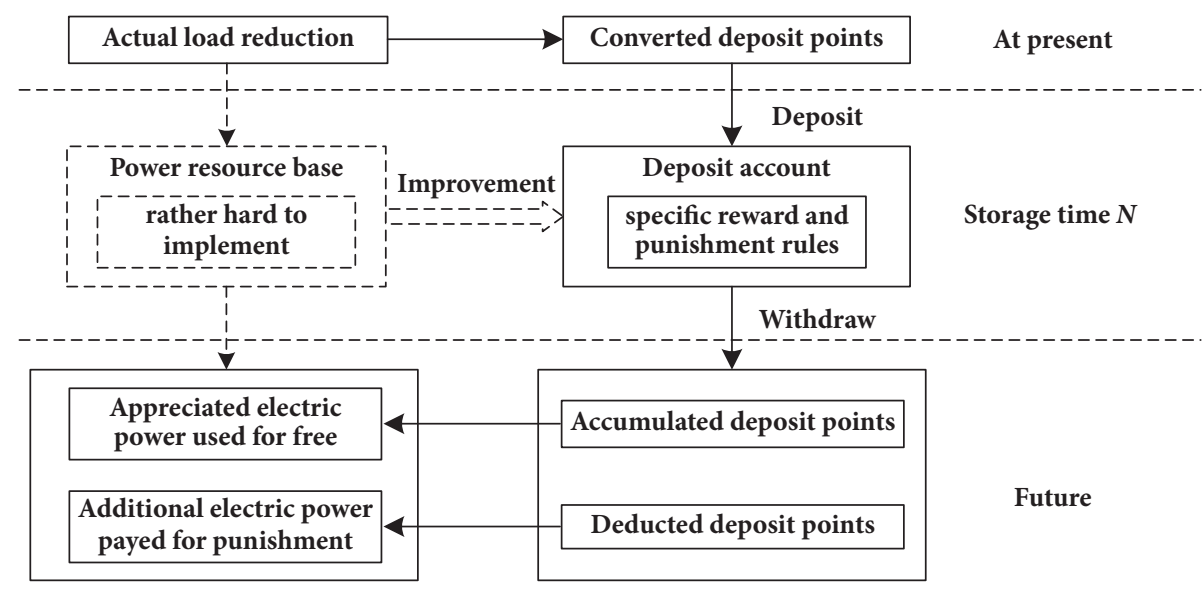

FIgURE 2: The principle of deposit point method for each customer.

achieve greater benefits by adjusting the production plan under deposit mechanism, leading to greater mobilization of customer motivation compared with traditional mechanism.

3.2. Reward and Punishment Rules. As is mentioned above, reward and punishment rules of deposit mechanism management are necessary to evaluate the effectiveness of customer's response. Once receiving notification from the power company, customers are selected as incentive targets and are supposed to voluntarily cut the load according to contractual contents. Otherwise, customers will be punished to pay additional penalties for their noncompliance.

Assume that the actual load reduction of a certain customer $k$ is $\Delta d_{k}(x)$ at incentive level $x$ within the duration of $T$. The steps of reward and punishment rules of deposit mechanism management can be summarized as follows:

(1) Calculate the converted deposit points $\left(M_{C}\right)$ of customer $k$ :

$$
M_{C, k}=M_{I N C, k}-M_{P E N, k}
$$

where $M_{I N C}$ is incentive points for compliance and $M_{P E N}$ is penalty points for noncompliance with the bilateral contract based on deposit mechanism.

$$
\begin{gathered}
M_{I N C, k}= \begin{cases}k_{1} \cdot d_{c u t, k} & \Delta d_{k}\left(x_{k}\right)>d_{c u t, k} \\
k_{1} \cdot \Delta d_{k}\left(x_{k}\right) & 0 \leq \Delta d_{k}\left(x_{k}\right) \leq d_{c u t, k} \\
0 & \Delta d_{k}\left(x_{k}\right)<0\end{cases} \\
M_{P E N, k} \\
= \begin{cases}0 & \Delta d_{k}\left(x_{k}\right)>d_{c u t, k} \\
k_{2} \cdot\left(d_{c u t, k}-\Delta d_{k}\left(x_{k}\right)\right) & 0 \leq \Delta d_{k}\left(x_{k}\right) \leq d_{c u t, k} \\
k_{2} \cdot d_{c u t, k} & \Delta d_{k}\left(x_{k}\right)<0\end{cases}
\end{gathered}
$$

where $k_{1}, k_{2}$ are incentive conversion ratio and penalty conversion ratio, respectively; $d_{c u t, k}$ is the contractual amount of load reduction.
(2) If $M_{C, k}>0$, customer response is in compliance with contractual requirements. Hence, $M_{C, k}$ is appreciated during the storage time $N$ :

$$
M_{B, k}=(1+x)^{N} \cdot M_{C, k}
$$

where incentive level is regarded as appreciated rate under deposit mechanism and $M_{B, k}$ is the appreciated points.

Customer $k$ can choose two ways as compensation for its regulated load reduction after storage time $N$. One is appreciated electric power used for free within the duration $T$ during valley periods; another is economic reimbursements. If customer $k$ fails to submit the application requiring for appreciated electric power usage, the power company defaults to compensate the customer economically.

If customer $k$ chooses to obtain free electric power in the future, the appreciated electricity $Q_{B, k}$ obtained during valley periods can be deduced as

$$
Q_{B, k}=\frac{M_{B, k}}{k_{1}} \cdot T
$$

If customer $k$ fails to submit the application, the economic reimbursements can be conducted in accordance with actual electricity reduction $Q_{C, k}$, which is deduced as

$$
Q_{C, k}=\Delta d_{k}(x) \cdot T
$$

(3) If $M_{C, k}=0$, customer response is in the critical state. Assign 0 to $Q_{B, k}$ under this circumstance. Customer $k$ does not need to pay additional penalties to the power company, nor can it receive any compensation.

(4) If $M_{C, k}<0$, customer response is defined as noncompliance. Penalties paid from customer $k$ to the power company are calculated based on penalty electricity $Q_{C, k}^{\prime}$ :

$$
Q_{C, k}^{\prime}=\frac{\left|M_{C, k}\right|}{k_{1}} \cdot T \cdot k_{c}
$$

where $k_{c}$ is the penalty rate for customer's noncompliance. 


\section{Decision Strategy of Capacity Shortage Event under Deposit Mechanism}

Under capacity shortage event, an appropriate decisionmaking strategy is capable of achieving maximum economic efficiency under the premise of guaranteeing the safety and stability of power system operation. The benefit model of subscribed customers and the power company under deposit mechanism are established in this section. Moreover, a decision strategy under deposit mechanism considering benefits of both the power company and the customers is proposed based on the uncertainty model of customer behaviour, with the purpose of achieving optimal incentive level (appreciated rate) of capacity shortage events. The main idea is to maximize total benefits of the power company on the premise of giving priority to customers with greater benefits as incentive targets. Eventually, the uniform design sampling (UDS) method considering correlations between different random input variables is introduced to quantify the uncertainties in decision strategy under deposit mechanism.

4.1. Benefit Model of the Subscribed Customer. According to the reward and punishment rules of deposit mechanism management, total benefits of customer $k\left(B E N_{k}\right)$ under deposit mechanism can be deduced as the following function:

$$
\begin{aligned}
& B E N_{k}=E\left\{u_{k}\left(\rho_{p e a k}-b_{p, k}\right) Q_{C, k}\right. \\
& \quad+u_{k} P_{j, k}\left[\alpha_{k} b_{v, k} Q_{B, k}+\left(1-\alpha_{k}\right) \rho_{c o m} Q_{C, k}\right] \\
& \left.\quad-u_{k}\left(1-P_{j, k}\right) \rho_{p e a k} Q_{C, k}^{\prime}\right\}
\end{aligned}
$$

where $E\{\bullet\}$ represents the mathematical expectation; $u_{k}$ is a state variable whose value is neither 0 or 1 ; if customer $k$ is one of the participants, then $u_{k}=1$, else $u_{k}=0 ; b_{p, k}$ and $b_{v, k}$ are unit production efficiency of customer $k$ during peak periods and valley periods, respectively $(\$ / \mathrm{kWh}) ; \rho_{\text {peak }}$ is peak electricity price $(\$ / \mathrm{kWh}) ; \alpha_{k}$ is the probability when customer $k$ submits the application for choosing appreciated electric power as the compensation; $\rho_{\text {com }}$ is the economic reimbursement for unit electricity reduction $(\$ / \mathrm{kWh}) ; P_{j, k}$ is the probability of compliance for customer $k$ under capacity shortage event $j$, which can be calculated through uniform design sampling (UDS) method introduced in this paper.

4.2. Benefit Model of the Power Company. Total benefits of the power company under deposit mechanism are introduced as follows based on the reward and punishment rules of deposit mechanism management:

$$
E_{c o m}=E_{c o m, 1}+E_{c o m, 2}-E_{c o m, 3}-E_{c o m, 4}-E_{c o m, 5}
$$

where $E_{c o m, 1}$ is avoidable investing and operating costs; $E_{\text {com }, 2}$ is penalties from customers; $E_{c o m, 3}$ is the loss of electricity sales; $E_{\text {com }, 4}$ is incentive costs; $E_{c o m, 5}$ is directly load shedding costs.

$$
\begin{aligned}
& E_{\text {com }, 1}=E\left\{\sum_{k=1}^{n} u_{k}\left[\left(C_{1}+C_{2}\right) Q_{C, k}\right]\right\} \\
& E_{\text {com }, 2}=E\left\{\sum_{k=1}^{n} u_{k}\left(1-P_{j, k}\right) \rho_{\text {peak }} Q_{C, k}^{\prime}\right\} \\
& E_{\text {com }, 3}=E\left\{\sum_{k=1}^{n} u_{k} \rho_{\text {peak }} Q_{C, k}\right\} \\
& E_{\text {com }, 4} \\
& =E\left\{\sum_{k=1}^{n} u_{k}\left[\alpha_{k} \rho_{\text {valley }} Q_{B, k}+\left(1-\alpha_{k}\right) \rho_{\text {com }} Q_{C, k}\right] P_{j, k}\right\} \\
& E_{\text {com }, 5}=E\left\{V O L L \cdot\left(C S_{j}-\sum_{k=1}^{n} u_{k} Q_{C, k}\right)\right\}
\end{aligned}
$$

where $E\{\bullet\}$ represents the mathematical expectation; $C_{1}$ is peak load pricing which represents the unit avoidable investment and operation costs of generators $(\$ / \mathrm{kWh}) ; C_{2}$ is unit transmission and distribution cost which represents the unit avoidable construction, operation, and maintenance costs of power networks $(\$ / \mathrm{kWh}) ; \rho_{\text {valley }}$ is valley electricity price ( $\$ / \mathrm{kWh}) ; \operatorname{VOLL}$ (value of lost load) is unit loss of directly load shedding when capacity shortage is not completely filled by subscribed customers $(\$ / \mathrm{kWh}) ; C S_{j}$ is the capacity deficiency of event $j$.

4.3. Decision Strategy. In general, the design and implementation of demand response mechanism, including deposit mechanism is to maximize the total benefits of the power company. However, benefits of subscribed customers chosen as incentive targets are also important in order to achieve greater participation motivation and promote a friendly bilateral interaction of power between suppliers and buyers considering the responsibilities of the power company. Hence, a novel decision strategy of capacity shortage events under deposit mechanism is proposed in this section to realize the economic efficiency of the power company on the premise of protecting benefits of subscribed customers, which helps to achieve a win-win situation for both the power company and the customers.

The objective of decision model is still maximizing total benefits of the power company:

$$
f=\max E_{\text {com }}
$$

Considering the uncertainty of customer behaviours, response fluctuation level of capacity shortage event $j$ can be defined as

$$
F_{j}=\frac{\left|\sum_{k=1}^{n} Q_{C, k}-C S_{j}\right|}{C S_{j}}
$$


Therefore, the reliability $R_{j}$ of capacity shortage event $j$, which evaluates the actual response of target customers, is deduced as follows:

$$
R_{j}=1-F_{j}
$$

Constraints of the decision model include the individualrationality constraint, load reduction constraint, reliability constraint, and incentive level (appreciated rate) constraint, which are shown as follows:

(1) Individual-Rationality Constraint. The expected benefit of customer $k$ chosen as an incentive target of capacity shortage event $j$ under deposit mechanism should be greater than the maximum expected benefit from nonparticipation $(k=$ $1,2, \ldots, n)$ :

$$
\left[\rho_{\text {peak }}+\left(1-\alpha_{k}\right) \rho_{c o m}\right] Q_{C, k}+\alpha_{k} b_{v, k} Q_{B, k} \geq b_{p, k} Q_{C, k}
$$

(2) Load Reduction Constraint. The actual load reduction of customer $k$ should not be less than the minimum interruption requirement $d_{\text {min }}$, which is usually defined as $0.5 \mathrm{MW}$ in China:

$$
\Delta d_{k}(x) \geq d_{\min } \quad k=1,2, \ldots, n
$$

(3) Reliability Constraint. In order to avoid the situations of "underresponse" and "overresponse", the range of reliability should be refined as

$$
R_{j, \min } \leq R_{j} \leq R_{j, \max }
$$

where $R_{j, \min }$ and $R_{j \text {, max }}$ are the lower/upper bounds of reliability.

(4) Incentive Level (Appreciated Rate) Constraint.

$$
x_{\min } \leq x \leq x_{\max }
$$

where $x_{\min }$ and $x_{\max }$ are the lower/upper bounds of incentive level (appreciated rate).

The decision strategy procedure of capacity shortage event $j$ can be summarized in Figure 3, where $N U M_{j, k}$ is the summation of compliance in random sampling; $N_{\text {sum }}$ is the total number of sampling. Hence, $P_{j, k}$ can be calculated as

$$
P_{j, k}=\frac{N U M_{j, k}}{N_{\text {sum }}}
$$

The steps of decision strategy can be explained in detail as follows.

Step 1. Acquire the deficiency of capacity shortage $C S_{j}$; Suppose the initial incentive level as well as its step length of event $j$.

Step 2. Among all the subscribed customers, choose those with maximum self-benefits as incentive targets at incentive level $x_{j}$, in which way the total benefits of subscribed customers are guaranteed to enhance the participation motivation of customers.
Step 3. Generate the sampling of actual load reduction $\Delta d_{k}\left(x_{j}\right)$ for each chosen customer $k$ chosen as incentive target based on the uniform design sampling (UDS) method.

Step 4. Calculate the probability of compliance $P_{j, k}$ for customer $k$ based on the sample statistics results as well as the reward and punishment rules of deposit mechanism.

Step 5. If the chosen customer $k$ cannot satisfy constraints (1) and (2), reselect an incentive target at the current incentive level $x_{j}$ according to the principle of maximum customer benefits among the rest of subscribed customers; repeat Steps 2 and 3; if all the chosen customers can satisfy constraints (1) and (2), calculate the reliability of capacity shortage event $j$ considering the actual load reductions of all incentive targets.

Step 6. If constraint (3) is satisfied, calculate total benefits of the power company at the current incentive level $x_{j}$.

Step 7. If incentive level has already reached the maximum set in constraint (4), output the optimal benefits of the power company as well as the incentive level.

4.4. Uniform Design Sampling (UDS) Method. Uncertainties of customers' actual load reductions lead to numerous random input variables in the decision strategy model. Hence, the uniform design sampling (UDS) method is introduced in this section considering the correlation between different random input variables.

Uniform design sampling (UDS) method is conducted based on the idea of space filling with sampling points obeying uniform distribution within the test range [32]. After sampling points are selected, edge transformation and correlation processing are put forward as well to enhance the universality of UDS. Compared with traditional Monte Carlo simulation, superiorities of UDS are presented as follows: (1) the number of sampling points of UDS is smaller with the same sample space; (2) the stability of UDS is better.

(1) Uniform Design Sampling. Assume that there are $\mathrm{m}$ dimensional random variables $X_{1}, X_{2}, \ldots, X_{m}$ obeying uniform distribution in interval $[0,1]$ and the total number of sampling points for each variable is $N_{c}$. Therefore, the steps of constructing sample moment $\boldsymbol{X}_{m \times N_{c}}$ by UDS are summarized as follows:

(1) Generate a positive integer vector $\boldsymbol{H}_{1 \times m}=\left[h_{1}, h_{2}, \ldots\right.$, $\left.h_{m}\right]$, where $h_{1}=1,1<h_{j}<n$, and for any $i \neq j, h_{i} \neq h_{j} ; n$ can be any positive integer greater than $m$.

(2) Generate vector $\mathbf{B}_{1 \times m}=\left[b_{1}, b_{2}, \ldots, b_{m}\right]$ with elements selected from $\left[0,1, \ldots, N_{c}-1\right]$.

(3) Generate sample matrix $\boldsymbol{E}_{m \times N_{c}}=\left[\boldsymbol{e}_{1}, \boldsymbol{e}_{2}, \ldots, \boldsymbol{e}_{i}, \ldots\right.$, $\left.\boldsymbol{e}_{m}\right]^{T}$ by traditional Monte Carlo simulation, where $e_{i}=$ $\left[e_{i 1}, e_{i 2}, \ldots, e_{i N_{c}}\right]$. Any $e_{i j}$ is supposed to obey uniform distribution in interval $[-0.5,0.5]$.

(4) Elements in $\boldsymbol{X}_{m \times N_{c}}=\left[\boldsymbol{x}_{1}, \boldsymbol{x}_{2}, \ldots \boldsymbol{x}_{i}, \ldots \boldsymbol{x}_{m}\right]^{T}$ can be defined as follows when $\boldsymbol{x}_{i}=\left[x_{i 1}, x_{i 2}, \ldots, x_{i N_{c}}\right]^{T}$ :

$$
x_{i j}=\left\{\frac{j h_{i}+b_{i}-0.5}{N_{c}}\right\}+\frac{e_{i j}}{N_{c}}
$$




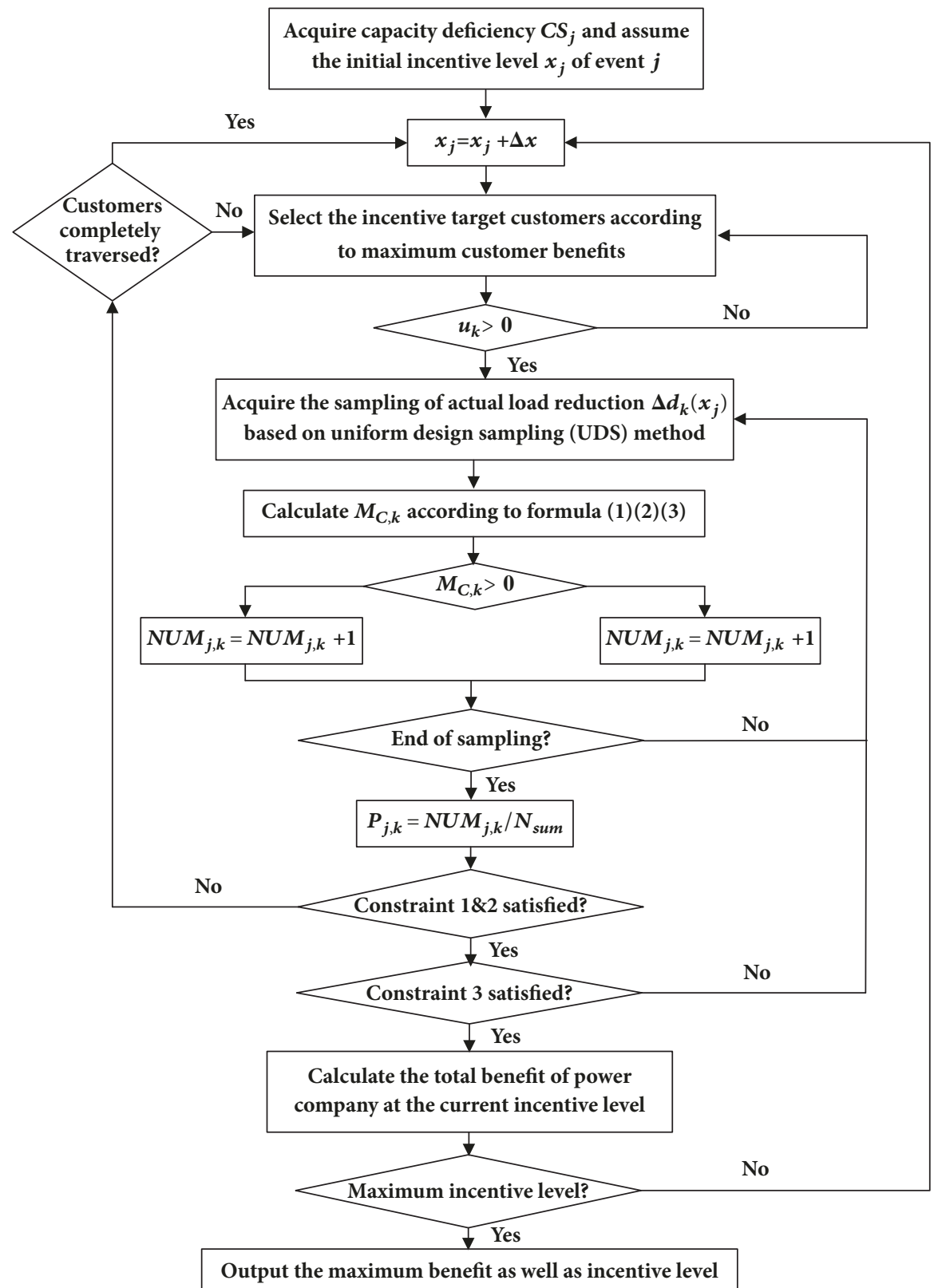

FIGURE 3: The decision strategy procedure of capacity shortage event $j$.

where $\{\bullet\}$ means taking the fractional part only; $i=1,2$, $\ldots, m ; j=1,2, \ldots, N_{c}$.

(2) Edge Transformation and Correlation Processing. It is noticed that random variables should obey uniform distribution in interval $[0,1]$, which is the basis of UDS. However, random variables in the stochastic model can be subject to arbitrary distributions. Therefore, edge transformation is proposed to solve this problem.

If the cumulative distribution function (CDF) of random input variable $\omega$ is referred to as $F(\omega)$, it can be confirmed that $u=F(\omega)$ is bound to obey uniform distribution in interval $[0,1][33]$. The transaction between those two different distributions is defined as edge transformation.

$$
F_{1}(y)=F(\omega) \Longleftrightarrow \omega=F^{-1}\left(F_{1}(y)\right)
$$

In this way, it is possible to implement transformation from uniform distribution to arbitrary distribution, which enhances the applicability of UDS.

The initial correlation coefficient matrix $\sum=\left(\gamma_{i j}\right)$ for input variables can either be calculated through measurement data or be directly given for those without measurement. As is mentioned above, edge transformation is capable of implementing transformation from uniform distribution to arbitrary distribution. In order to satisfy the initial correlation between input variables after edge transformation, an intermediate variable $v^{\prime}$ obeying Gaussian distribution is 
TABLE 1: Characteristic parameters of typical customers.

\begin{tabular}{lcccccccc}
\hline Type & $\Delta d_{0} /$ capacity & $\Delta d_{\max } /$ capacity & $x_{0}$ & $x_{1}$ & $x_{\max }$ & $d_{\text {cut }} /$ capacity & $k_{c}$ & $\alpha$ \\
\hline 1 & $8 \%$ & $40 \%$ & 0.05 & 0.10 & 0.20 & $40 \%$ & $25 \%$ & 1.2 \\
2 & $5 \%$ & $25 \%$ & 0.05 & 0.20 & 0.30 & 0.8 \\
3 & $3 \%$ & $10 \%$ & 0.05 & 0.30 & 0.40 & $10 \%$ & \\
\hline
\end{tabular}

TABLE 2: Optimal benefits of customers under deposit mechanism and traditional mechanism.

\begin{tabular}{lcrr}
\hline Mechanism & Customer type & Optimal benefit/\$ & Incentive range when $B E N \geq 0$ \\
\hline \multirow{2}{*}{ Traditional mechanism } & 1 & 562.05 & {$[0.136,0.2]$} \\
& 2 & 492.95 & {$[0.233,0.3]$} \\
Deposit mechanism & 3 & 243.41 & {$[0.325,0.4]$} \\
& 1 & 858.68 & {$[0.146,0.2]$} \\
& 2 & 738.71 & {$[0.236,0.3]$} \\
\hline
\end{tabular}

introduced for correlation processing. Main steps of correlation processing are summarized as follows:

(1) Assume that the sample matrix generated by UDS is $\boldsymbol{Y}_{m \times N_{c}}, \boldsymbol{Y}_{m \times N_{c}}=\left[\boldsymbol{y}_{1}, \boldsymbol{y}_{2}, \ldots, \boldsymbol{y}_{i}, \ldots, \boldsymbol{y}_{m}\right]^{T}, \boldsymbol{y}_{i} \sim U(0,1)$. The corresponding intermediate variable $\boldsymbol{v}_{i}$ can be achieved as

$$
\boldsymbol{v}_{i}=\Phi^{-1}\left(\boldsymbol{y}_{i}\right) \quad i=1,2, \ldots, m
$$

where $\Phi$ is CDF of standard normal distribution.

(2) Make a corresponding correction to the initial correlation coefficient matrix $\sum$. For the transformation from Gaussian distribution to uniform distribution, the nondiagonal elements of $\sum$ should be modified as [34]

$$
\gamma_{i j}^{*}=2 \sin \left(\frac{\pi}{6} \gamma_{i j}\right)
$$

The revised correlation coefficient matrix is denoted as $\sum^{*}=$ $\left(\gamma_{i j}^{*}\right)$.

(3) Achieve the corresponding Gaussian sample matrix $\boldsymbol{V}^{\text {corr }}$ by Cholesky decomposition of $\sum^{*}$ :

$$
\boldsymbol{V}^{\text {corr }}=\boldsymbol{L} \boldsymbol{V}
$$

where $\boldsymbol{V}=\left[\boldsymbol{v}_{1}, \boldsymbol{v}_{2}, \ldots, \boldsymbol{v}_{i}, \ldots, \boldsymbol{v}_{n}\right]^{T}, \boldsymbol{v}_{i}=\left[v_{i 1}, v_{i 2}, \ldots, v_{i N_{c}}\right], \boldsymbol{L}$ is an upper triangular matrix which satisfies $\sum^{*}=\mathbf{L L}^{T}$.

(4) Achieve the corresponding uniform sample as

$$
y_{i}^{\text {corr }}=\Phi\left(\boldsymbol{v}_{i}^{\text {corr }}\right)
$$

Another edge transformation is also necessary to obtain the corresponding sample of input variable $\omega_{i}$ :

$$
\boldsymbol{\omega}_{i}^{\text {corr }}=\boldsymbol{F}_{w_{i}}^{-1}\left(\boldsymbol{y}_{i}^{\text {corr }}\right) \quad i=1,2, \ldots, m
$$

where $\boldsymbol{F}_{w_{i}}$ is CDF of input variable $\omega_{i}$.

Due to the nonlinear characteristics of edge transformation, truncation errors may occur in the process [35]. Usually, the errors are too small to have effect on results. Therefore, the truncation errors are ignored in this paper.

\section{Case Studies and Discussions}

Taking the electricity data in Nanjing city, China, as an example, peak electricity price $\rho_{\text {peak }}$ is $0.2 \$ / \mathrm{kWh}$ and valley electricity price $\rho_{\text {valley }}$ is $0.08 \$ / \mathrm{kWh}$ according to market survey. Considering the significant economic benefits of demand response, peak load pricing $\mathrm{C}_{1}$ and unit transmission and distribution cost $C_{2}$ are assumed as $0.7 \$ / \mathrm{kWh}$ and $0.015 \$ / \mathrm{kWh}$, respectively. VOLL is set as $1000 \$ / \mathrm{MWh}$ and the relationship between incentive conversion ratio and penalty conversion ratio $k_{1}$ is proposed as $k_{2}$ according to literature [36].

Under deposit mechanism, unit economic reimbursement $\rho_{\text {com }}$ cannot be set too high or too low. On the one hand, $\rho_{\text {com }}$ should be smaller than unit economic reimbursement under traditional mechanism in order to encourage power consumption during valley periods. On the other hand, $\rho_{\text {com }}$ is ought to be higher than peak electricity price $\rho_{\text {peak }}$ so as to guarantee effectiveness of incentive measures. As a result, $\rho_{\text {com }}$ is set as $0.28 \$ / \mathrm{kWh}$ in this paper [10].

5.1. Customer Benefits under Different Mechanisms. Three typical customer types under deposit mechanism based on the range of incentive levels are proposed in this section shown in Table 1. Assume that unit production efficiencies during peak and valley periods are 0.3385 and $0.2154 \$ / \mathrm{kWh}$, response time $T$ is 1 (hour), and storage time $N=3$ (months) for all three types of customers. Optimal benefits of each typical customer under deposit mechanism and traditional mechanism can be shown in Table 2 . In order to reveal the influence of customer types to customer benefits, the capacity is set as 10MW for all three types in this case.

Under traditional mechanism, customers can only receive economic compensations based on actual electricity reduction for compliance while the penalty rate for noncompliance is still $k_{c}$. Unit economic compensation under traditional mechanism is set as $0.3385 \$ / \mathrm{kWh}[10]$.

From customer's point of view, optimal benefits under deposit mechanism are superior to those under traditional mechanism owing to the fact that the scope of customer 
TABLE 3: Typical categories of customers' capacity allocation.

\begin{tabular}{lccc}
\hline \multirow{2}{*}{ Typical categories } & \multicolumn{2}{c}{ Capacity proportion of different customer types } \\
& Type 1 & Type 2 & Type 3 \\
\hline Category 1 & $50 \%$ & $25 \%$ & $25 \%$ \\
Category 2 & $25 \%$ & $50 \%$ & $25 \%$ \\
Category 3 & $25 \%$ & $25 \%$ & $50 \%$ \\
\hline
\end{tabular}
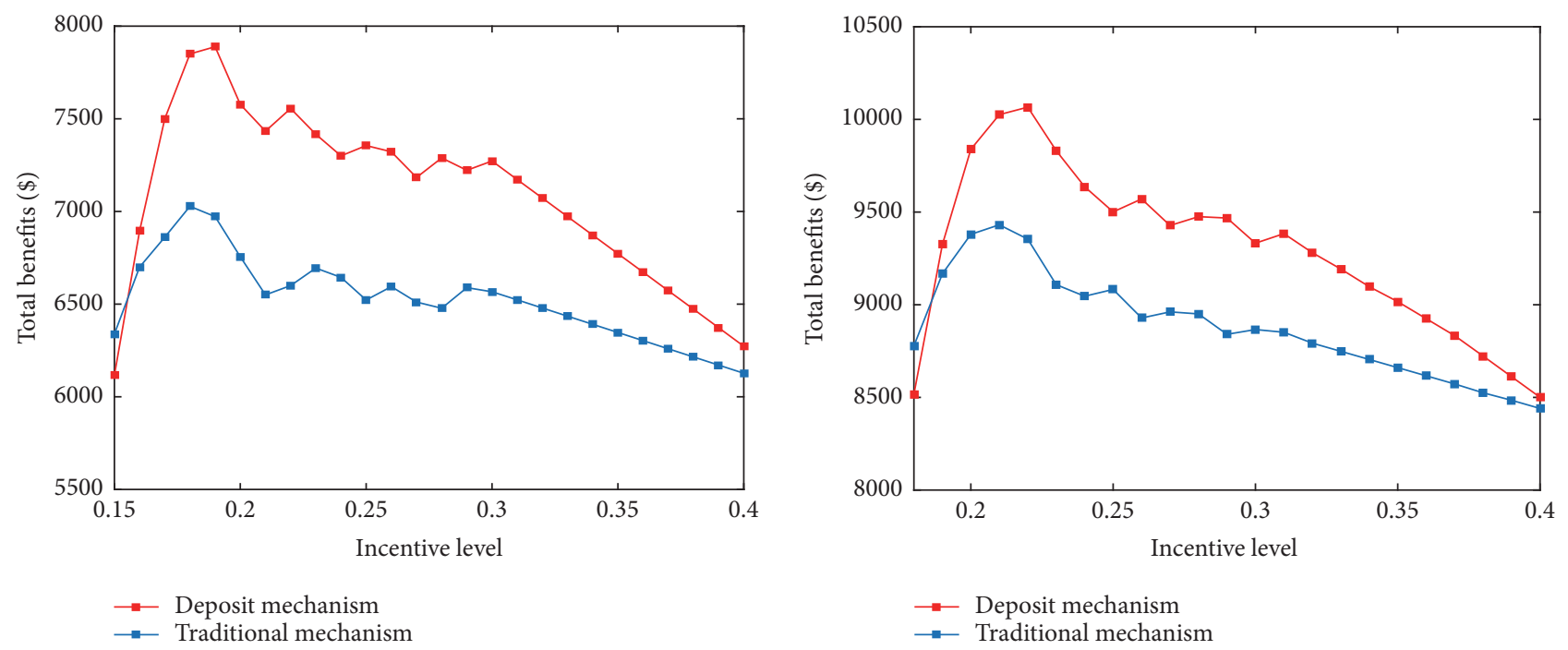

FIGURE 4: Comparison of the decision strategy results between deposit mechanism and traditional mechanism with customer allocation of category 1 under different scenarios. Left: scenario 1. Right: scenario 2.

benefits has been expanded under deposit mechanism with the appreciated function. In addition, customer in type 1 owns the maximum benefits and minimum profit range among all types due to its high sensitivity to changes in incentive levels and high flexibility in electricity usage, indicating that the participation willing of customers in type 1 may be the strongest under deposit mechanism.

\subsection{Decision Strategy Benefits under Different Mechanisms.} Assume that the total capacity of subscribed customers is $900 \mathrm{MW}$. In order to facilitate the analysis of decision results under deposit mechanism with different customer compositions, three typical categories of customers' capacity allocation are proposed in Table 3. The total number of customers is $n=30$ with 10 type 1 customers, 10 type 2 customers, and 10 type 3 customers. The capacity of each customer under a specific type is randomly generated but remains the same characteristics with that given in Table 1 . Because of the fact that subscribed customers are mutually independent, the initial correlation coefficient matrix is a null matrix. Two scenarios are also proposed to simulate different capacity shortage events that occurred during peak periods. The capacity gaps are $20 \mathrm{MW}$ and $35 \mathrm{MW}$ under scenario 1 and scenario 2, describing the actual electricity consumption situation during spring/autumn and summer/winter, respectively.

The comparison of decision strategy results (total benefits of the power company) between deposit mechanism and traditional mechanism with different categories of customer allocation under different scenarios is illustrated in Figures $4-6$, while the reliability range is set as $80 \%-90 \%$ in all cases. The lower limits of incentive level shown in Figures 4, 5, and 6 are the minimum incentive level satisfying reliability requirements in each specific scenario. The upper limits of incentive level shown in Figures 4, 5, and 6 are both 0.4, where all customers have reached saturated zone in all cases.

It is revealed from Figures 4-6 that the decision strategy results under deposit mechanism are superior to that under traditional mechanism in the most range of effective incentive level of all cases. It is because the optional compensation way of free appreciated electric power under deposit mechanism significantly reduces the overall incentive costs of the power company in the most range of effective inventive level compared with traditional mechanism, illustrating the great superiority of proposed deposit mechanism.

However, there is a tendency that the total benefits under deposit mechanism are inferior to those under traditional mechanism at the very beginning and ending of effective incentive range. Reasons for this phenomenon can be explained as follows. When incentive level is relatively low, customers are highly likely to be defined as noncompliance under deposit mechanism. Hence, the lack of motivation causes decrease of total load reduction, leading to less benefits under deposit mechanism. When incentive level is too high, the exponentially growing incentive costs caused by appreciated function under deposit mechanism are bigger than that 

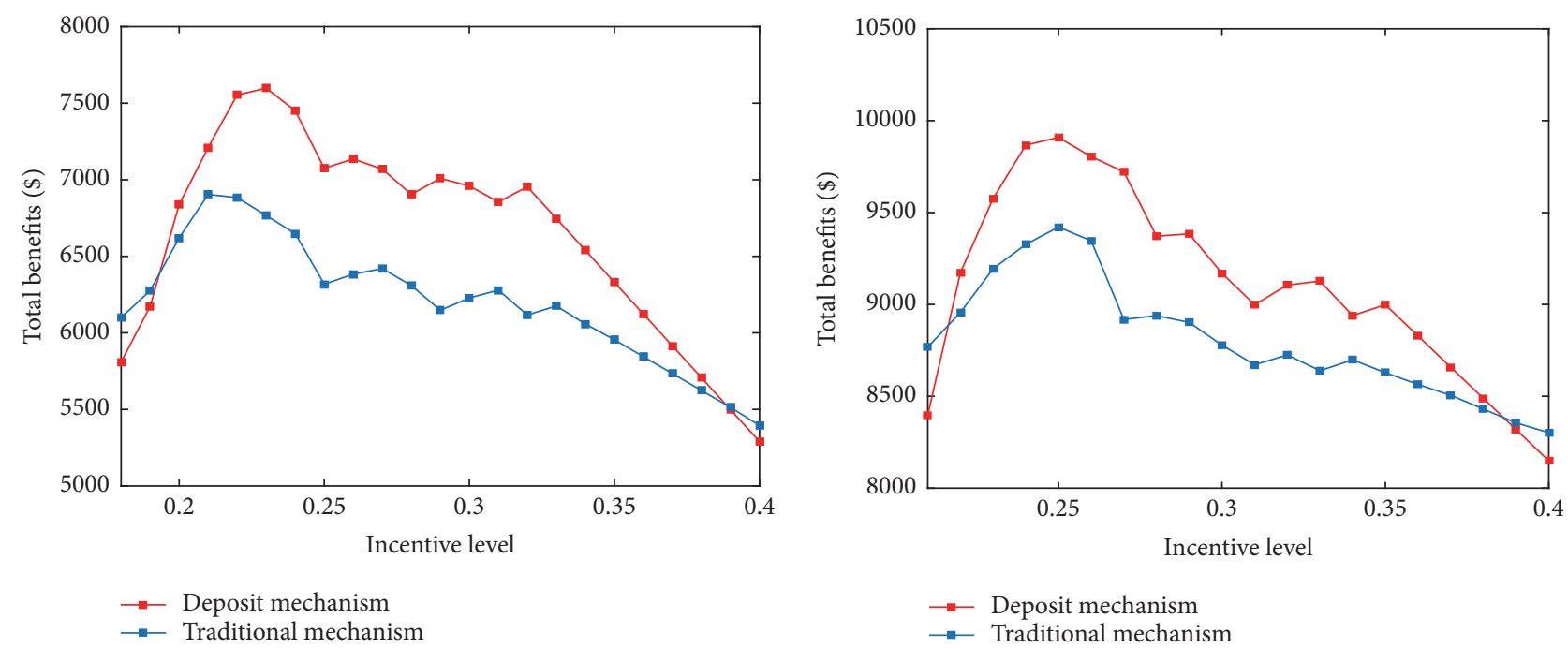

Figure 5: Comparison of the decision strategy results between deposit mechanism and traditional mechanism with customer allocation of category 2 under different scenarios. Left: scenario 1 . Right: scenario 2.

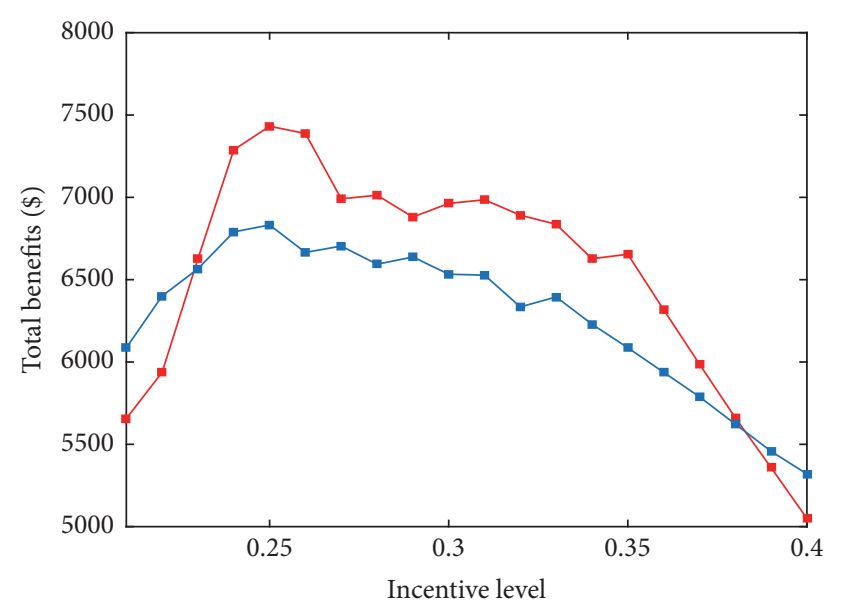

$\rightarrow$ Deposit mechanism

$\rightarrow$ Traditional mechanism

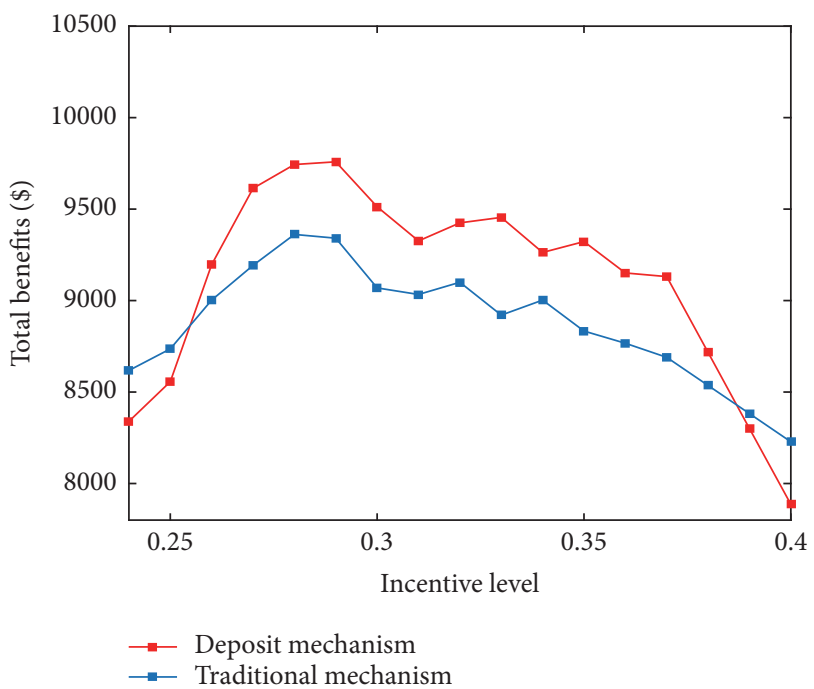

Figure 6: Comparison of the decision strategy results between deposit mechanism and traditional mechanism with customer allocation of category 3 under different scenarios. Left: scenario 1. Right: scenario 2.

growing linearly under traditional mechanism, leading to the steeper slope of deposit mechanism when incentive targets have been fixed.

In general, deposit mechanism still has outstanding advantages over traditional mechanism in the most range of effective incentive level ranges and the tendency inferior to traditional mechanism only appears in extreme cases with rather small probabilities.

It is also noted that the optimal benefits as well as the incentive range superior to traditional mechanism of deposit mechanism are successively decreasing with customer allocation of category 1, category 2, and category 3, mainly because of the different proportion of different customer types in the three categories. According to analysis above, type 1 customers are more sensitive to incentive level changes and with greater schedulable potential than type 2 and type 3 customers with the same capacity. As a result, the power company is capable of acquiring more demand side resources with less incentive costs from type 1 customers, leading to greater benefits under the same scenario. The more proportion type 1 customers accounted for, the greater benefits are.

The overall trends of total benefits curves with different categories of customer allocation and different scenarios are almost the same. As incentive level increases, customers with greater benefits are chosen as incentive targets and the actual load reduction improves as well, leading to the gradual increase of total benefits at the very beginning. With the continuous increases of incentive level, part of customers have reached the saturated zone, and other customers will 


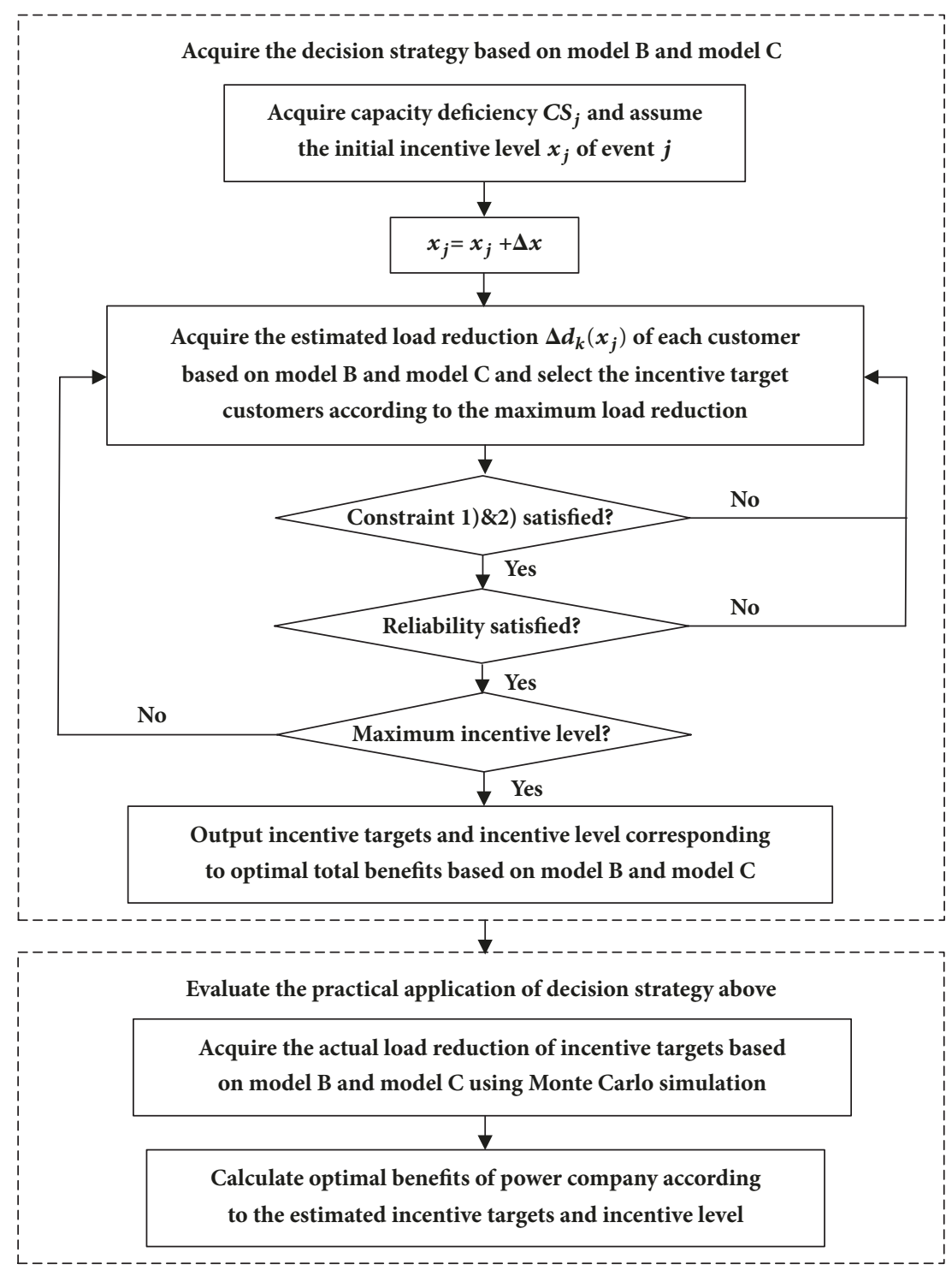

FIGURE 7: Analysis procedure of model B and model C.

be informed to reduce electric power in order to satisfy the reliability. Therefore, the growth in incentive costs causes the decrease of total benefits and the dynamic choices of incentive targets result in the fluctuation. As incentive level continues to increase and reaches a certain value, the selection of incentive targets has been fixed. After that, the increase of incentive costs causes the gradual decrease of total benefits.

\subsection{Efficacy of Proposed Uncertainty Customer Behaviour} Model. The influence of different modelling of customers for decision strategy under deposit mechanism is proposed in this section. Among them, model A is the uncertainty model previously noted in Section 2, and model B and model $\mathrm{C}$ are the traditional deterministic psychology models with different inflection points between dead zone and linear zone, representing the optimistic estimation and pessimistic estimation of actual load reduction, respectively. The traditional deterministic psychology model is introduced in the Appendix.

The inflection points of model $\mathrm{B}$ and model $\mathrm{C}$ are set as $x_{0}$ and $x_{1}$ of model A, respectively, while other parameters remain the same. Suppose the reliability is $80 \%-90 \%$ under scenario 1 with customer allocation of category 2 . The analysis procedure of models B and C is shown in Figure 7.

Key parameters of decision strategy results based on models A, B, and C are proposed in Table 4. It is illustrated that optimal benefits based on model A are superior to those based on model B and model C. If the actual load reduction of customers is optimistic estimated (model B), probability of noncompliance is higher and the penalties from customers will increase. However, the costs for directly load shedding will also increase, leading to the decline of optimal benefits. If the actual load reduction of customers is pessimistic estimated (model C), the increase of 
TABLE 4: Key parameters of decision strategy based on models A, B, C.

\begin{tabular}{lccccc}
\hline Model & $\begin{array}{c}\text { Optimal } \\
\text { incentive level }\end{array}$ & $\begin{array}{c}\text { Optimal } \\
\text { benefits/\$ }\end{array}$ & $\begin{array}{c}\text { Incentive } \\
\text { costs/\$ }\end{array}$ & $\begin{array}{c}\text { Compensation } \\
\text { from customers/\$ }\end{array}$ & $\begin{array}{c}\text { Directly load } \\
\text { shedding costs/\$ }\end{array}$ \\
\hline A & 0.23 & 7415.05 & 4216.01 & 13.48 & 419.48 \\
B & 0.16 & 5882.87 & 2819.40 & 89.22 & 2419.22 \\
C & 0.26 & 6806.51 & 4657.30 & 0 & 0 \\
\hline
\end{tabular}

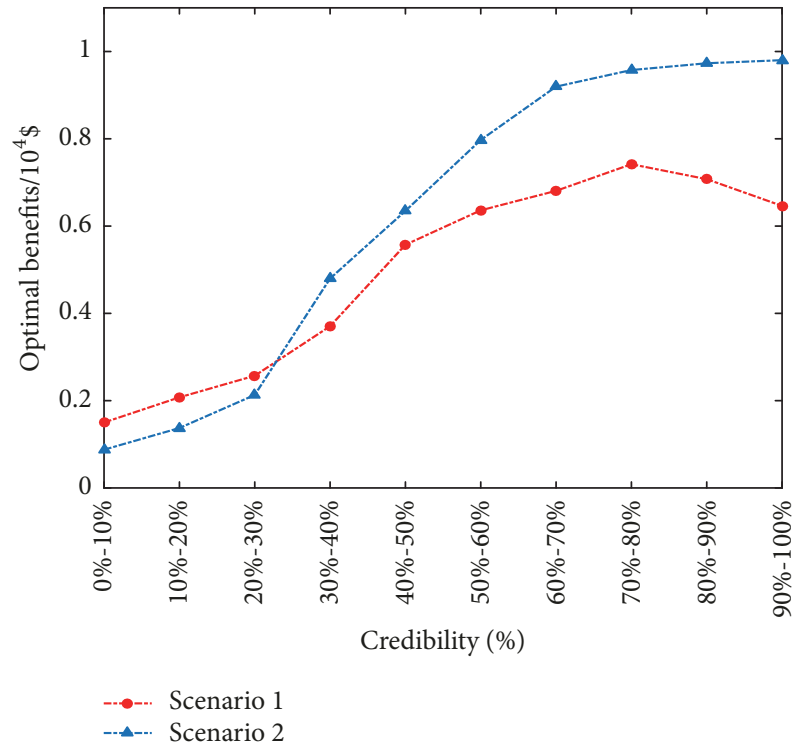

FIGURE 8: The trend of optimal benefits changing with reliability range with customer allocation of category 2 under different scenarios.

incentive costs will cause the decline of optimal benefits as well.

5.4. Influence of Reliability Setting on Decision Strategy. In order to further analyse the influence of reliability on decision strategy results, different reliability ranges are chosen under scenario 1 and scenario 2 with the customer allocation of category 2. The trend of optimal benefits changing with reliability range is shown in Figure 8.

From the perspective of the power company, optimal reliability ranges are $70 \%-80 \%$ under scenario 1 and $90 \%$ $100 \%$ under scenario 2 . Reasons for this phenomenon can be explained as follows. Under scenario 1, capacity gap is comparatively small. The influence of uncertainty in customer behaviours can be decreased along with the increase of incentive level in order to satisfy reliability requirements. However, as the reliability increases, the rising of incentive costs can also lead to the decline of optimal benefits. Under scenario 2, the electricity shortage is rather severe that the power company needs to continuously increase incentive level to encourage the participation of more customers so that capacity gap can be filled, owing to the fact that costs of direct load shedding caused by insufficient response are much higher than incentive costs. Customers with lower schedulable potential is selected as well due to the expansion

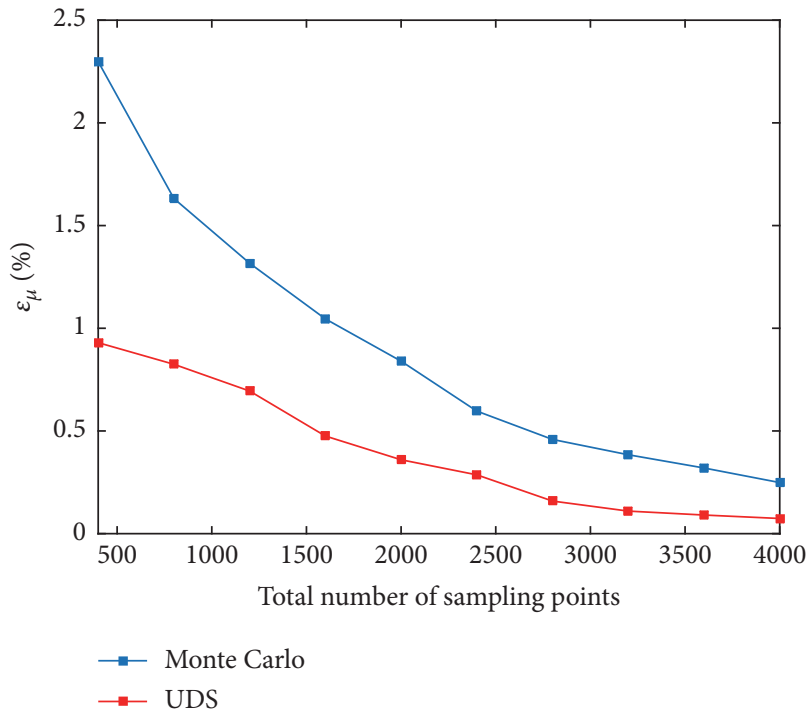

FIGURE 9: Error comparison of mean between Monte Carlo simulation and UDS.

of incentive targets, which can explain the gradual decrease of increasing rate in optimal benefits.

5.5. Comparison between UDS and Traditional Monte Carlo Simulation. The selection of input random sampling determines calculation accuracy directly. Suppose that results calculated by traditional Monte Carlo simulation with sampling scale of 40000 is the accurate value of optimal benefits. The accurate mean and variance can be described as $\mu_{\text {mean }}$ and $\sigma_{\text {var }}^{2}$, while the calculated mean and variance can be described as $\mu_{\text {cal }}$ and $\sigma_{\text {cal }}^{2}$. Therefore, average relative errors of optimal benefits are deduced as

$$
\begin{aligned}
& \varepsilon_{\mu}=\left|\frac{\mu_{\text {mean }}-\mu_{\text {cal }}}{\mu_{\text {mean }}}\right| \\
& \varepsilon_{\sigma}=\left|\frac{\sigma_{\mathrm{var}}^{2}-\sigma_{c a l}^{2}}{\sigma_{\mathrm{var}}^{2}}\right|
\end{aligned}
$$

where $\varepsilon_{\mu}$ is average relative error of mean and $\varepsilon_{\sigma}$ is average relative error of variance.

The relative errors of optimal benefits solved by traditional Monte Carlo simulation and UDS are shown in Figures 9 and 10. It is indicated that UDS is superior to Monte Carlo simulation in terms of precision as well as error stability with the same sample size. The fewer sampling points are, the greater advantages can be illustrated. 


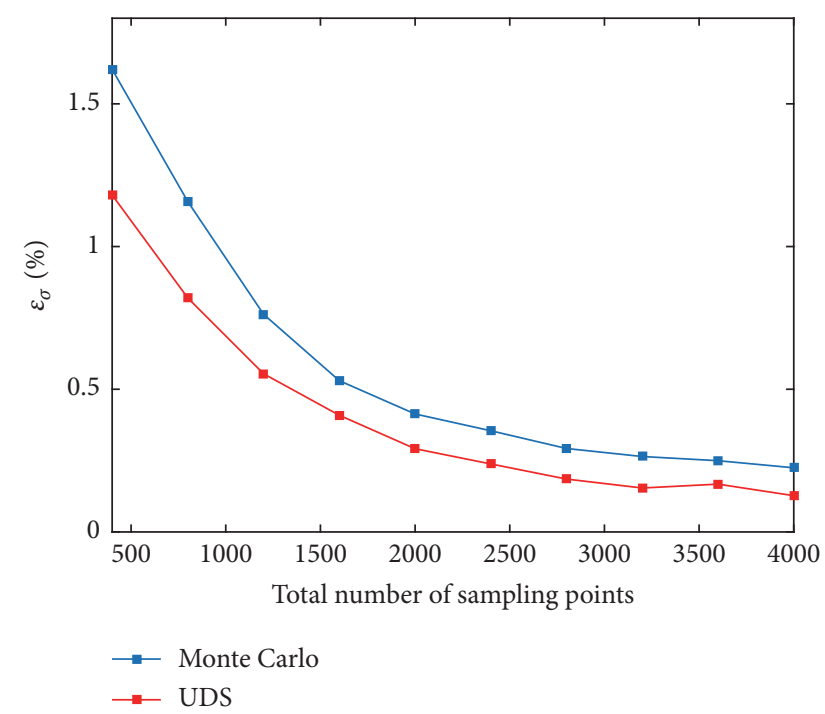

Figure 10: Error comparison of variance between Monte Carlo simulation and UDS.

\section{Conclusions}

In this paper, the design of deposit mechanism and a novel corresponding decision strategy are proposed considering the uncertainty of customer behaviour. Based on the theory of customer psychology, an uncertainty model of customer behaviour is introduced. Emulating the deposit and withdrawal process of bank funds, a new deposit point method is proposed and applied into the deposit mechanism design to realize the storage and value-added function of deposit points converted from electric power. Furthermore, a decision strategy based on uncertainty model of customer behaviour is proposed considering both the benefits of the power company and the subscribed customers under deposit mechanism. Uncertainties in decision strategy are quantified by uniform design sampling (UDS) method. In general, the advantages of proposed deposit mechanism and decision strategy as well as its uncertainty quantification method are the following: (1) Greater benefits of both the power company and the subscribed customers are to be obtained. (2) A win-win situation and greater mobilization of customer motivation can be achieved. (3) The influence caused by estimation of customer behaviour can be reduced. (4) Sampling efficiency, computational accuracy, and error stability can be improved. With the electricity data of Nanjing city, China, the numerical simulation results demonstrate that the proposed deposit mechanism and decision strategy can improve the effectiveness of DR in China. Compared with traditional methods, greater benefits of both the power company and the customers can be achieved to improve the participation motivation of customers.

\section{Appendix}

The traditional deterministic psychology model of customer response mentioned in Section 5 is shown in Figure 11.

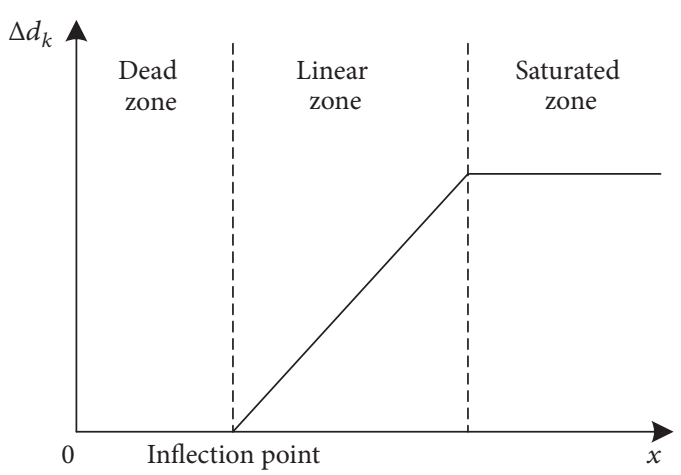

FIGURE 11: Traditional deterministic psychology model of customer response.

\section{Data Availability}

All the data needed in decision strategy solution has been presented in the main body of this paper.

\section{Conflicts of Interest}

The authors declare no conflicts of interest.

\section{Acknowledgments}

This research was funded by National Key Technology Research and Development Program of China [2016YFB0901100].

\section{References}

[1] Q. Xu, Y. Ding, Q. Yan, A. Zheng, and P. Du, "Day-Ahead Load Peak Shedding/Shifting Scheme Based on Potential Load Values Utilization: Theory and Practice of Policy-Driven Demand Response in China," IEEE Access, vol. 5, pp. 22892-22901, 2017.

[2] R. Deng, Z. Yang, J. Chen, and M.-Y. Chow, "Load scheduling with price uncertainty and temporally-coupled constraints in smart grids," IEEE Transactions on Power Systems, vol. 29, no. 6, pp. 2823-2834, 2014.

[3] Y. Wang, Q. Xu, Z. Ma, and H. Zhu, "An improved control and energy management strategy of three-level NPC converter based DC distribution network," Energies, vol. 10, no. 10, 2017.

[4] Y. Wang, Q. Xu, and M. Liu, "A novel system operation mode with flexible bus type selection method in DC power systems," International Journal of Electrical Power \& Energy Systems, vol. 103, pp. 1-11, 2018.

[5] P. Siano, "Demand response and smart grids-a survey," Renewable \& Sustainable Energy Reviews, vol. 30, pp. 461-478, 2014.

[6] H. A. Aalami, M. P. Moghaddam, and G. R. Yousefi, "Demand response modeling considering interruptible/curtailable loads and capacity market programs," Applied Energy, vol. 87, no. 1, pp. 243-250, 2010.

[7] J. Saez-Gallego, J. M. Morales, M. Zugno, and H. Madsen, "A Data-Driven Bidding Model for a Cluster of Price-Responsive Consumers of Electricity," IEEE Transactions on Power Systems, vol. 31, no. 6, pp. 5001-5011, 2016. 
[8] F. Aminifar, M. Fotuhi-Firuzabad, and M. Shahidehpour, "Unit commitment with probabilistic spinning reserve and interruptible load considerations," IEEE Transactions on Power Systems, vol. 24, no. 1, pp. 388-397, 2009.

[9] G. K. Toh and H. B. Gooi, "Procurement of interruptible load services in electricity supply systems," Applied Energy, vol. 98, pp. 533-539, 2012.

[10] M. M. Sahebi, E. A. Duki, M. Kia, A. Soroudi, and M. Ehsan, "Simultanous emergency demand response programming and unit commitment programming in comparison with interruptible load contracts," IET Generation, Transmission \& Distribution, vol. 6, no. 7, pp. 605-611, 2012.

[11] R. Argiento, R. Faranda, A. Pievatolo, and E. Tironi, "Distributed interruptible load shedding and micro-generator dispatching to benefit system operations," IEEE Transactions on Power Systems, vol. 27, no. 2, pp. 840-848, 2012.

[12] H.-G. Park, J.-K. Lyu, Y. Kang, and J.-K. Park, "Unit commitment considering interruptible load for power system operation with wind power," Energies, vol. 7, no. 7, pp. 4281-4299, 2014.

[13] R. Bhana and T. J. Overbye, "The Commitment of Interruptible Load to Ensure Adequate System Primary Frequency Response," IEEE Transactions on Power Systems, vol. 31, no. 3, pp. 2055-2063, 2016.

[14] J. Dong, G. Xue, and R. Li, "Demand response in China: Regulations, pilot projects and recommendations - A review," Renewable \& Sustainable Energy Reviews, vol. 59, pp. 13-27, 2016.

[15] J. Sousa, O. R. Saavedra, and S. L. Lima, "Decision-Making in Emergency Operation for Power Transformers with Regard to Risks and Interruptible Load Contracts," IEEE Transactions on Power Delivery, vol. 99, 2017.

[16] M. Shafie-Khah and J. P. S. Catalão, "A stochastic multi-layer agent-based model to study electricity market participants behavior," IEEE Transactions on Power Systems, vol. 30, no. 2, pp. 867-881, 2015.

[17] H.-G. Kwag and J.-O. Kim, "Reliability modeling of demand response considering uncertainty of customer behavior," Applied Energy, vol. 122, pp. 24-33, 2014.

[18] N. Nikmehr, S. Najafi-Ravadanegh, and A. Khodaei, "Probabilistic optimal scheduling of networked microgrids considering time-based demand response programs under uncertainty," Applied Energy, vol. 198, pp. 267-279, 2017.

[19] Q. Zhang, M. F. Morari, I. E. Grossmann, A. Sundaramoorthy, and J. M. Pinto, "An adjustable robust optimization approach to scheduling of continuous industrial processes providing interruptible load," Computers \& Chemical Engineering, vol. 86, pp. 106-119, 2016.

[20] Q. Wang, J. Wang, and Y. Guan, "Stochastic unit commitment with uncertain demand response," IEEE Transactions on Power Systems, vol. 28, no. 1, pp. 562-563, 2013.

[21] M. Aien, M. Fotuhi-Firuzabad, and M. Rashidinejad, "Probabilistic optimal power flow in correlated hybrid windphotovoltaic power systems," IEEE Transactions on Smart Grid, vol. 5, no. 1, pp. 130-138, 2014.

[22] Z. Wei, J. Xu, X. Dai et al., "Research on coarse-grained parallel algorithm of the Monte-Carlo simulation for probabilistic load flow calculation," Power and Energy, 2015.

[23] C. Delgado and J. A. Domínguez-Navarro, "Point estimate method for probabilistic load flow of an unbalanced power distribution system with correlated wind and solar sources," International Journal of Electrical Power \& Energy Systems, vol. 61, pp. 267-278, 2014.
[24] W. Wu, K. Wang, B. Han et al., "A versatile probability model of photovoltaic generation using pair copula construction," Power and Energy Society General Meeting, 2016.

[25] A. Tamtum, A. Schellenberg, and W. D. Rosehart, "Enhancements to the cumulant method for probabilistic optimal power flow studies," IEEE Transactions on Power Systems, vol. 24, no. 4, pp. 1739-1746, 2009.

[26] M. D. Shields and J. Zhang, "The generalization of Latin hypercube sampling," Reliability Engineering \& System Safety, vol. 148, pp. 96-108, 2016.

[27] Q. Xu, Y. Yang, Y. Liu, and X. Wang, "An improved latin hypercube sampling method to enhance numerical stability considering the correlation of input variables," IEEE Access, vol. 5, pp. 15197-15205, 2017.

[28] S. Majumdar, D. Chattopadhyay, and J. Parikh, "Interruptible load management using optimal power flow analysis," IEEE Transactions on Power Systems, vol. 11, no. 2, pp. 715-720, 1996.

[29] M. Feldstein and C. Horioka, "Domestic saving and international capital flows," Economic Journal, vol. 90, no. 358, pp. 314329,1980

[30] J. H. Doudna, "Overview of California ISO summer 2000 demand response programs," in Proceedings of the 2001 IEEE Power Engineering Society Winter Meeting, vol. 1, pp. 228-233, 2001.

[31] N. Abed, S. Greene, and J. Gentile T, "New York Independent System Operator (NYISO) Benefits of Adding Capacitors to the Electric System February 27," Keats-Shelley Journal, pp. 151-153, 2008.

[32] K.-T. Fang, D. K. Lin, P. Winker, and Y. Zhang, "Uniform design: theory and application," Technometrics, vol. 42, no. 3, pp. 237$248,2000$.

[33] P.-L. Liu and A. der Kiureghian, "Multivariate distribution models with prescribed marginals and covariances," Probabilistic Engineering Mechanics, vol. 1, no. 2, pp. 105-112, 1986.

[34] J. Usaola, "Probabilistic load flow with correlated wind power injections," Electric Power Systems Research, vol. 80, no. 5, pp. 528-536, 2010.

[35] H. Li, Z. Lü, and X. Yuan, "Nataf transformation based point estimate method," Chinese Science Bulletin, vol. 53, no. 17, pp. 2586-2592, 2008.

[36] A. Moshari, A. Ebrahimi, and M. Fotuhi-Firuzabad, "ShortTerm Impacts of DR Programs on Reliability of Wind Integrated Power Systems Considering Demand-Side Uncertainties," IEEE Transactions on Power Systems, vol. 31, no. 3, pp. 2481-2490, 2016. 


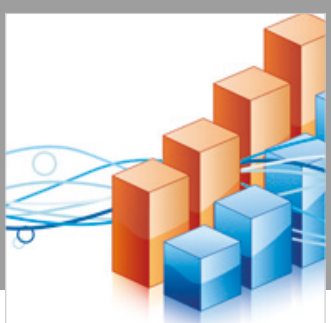

Advances in

Operations Research

\section{-n-m}
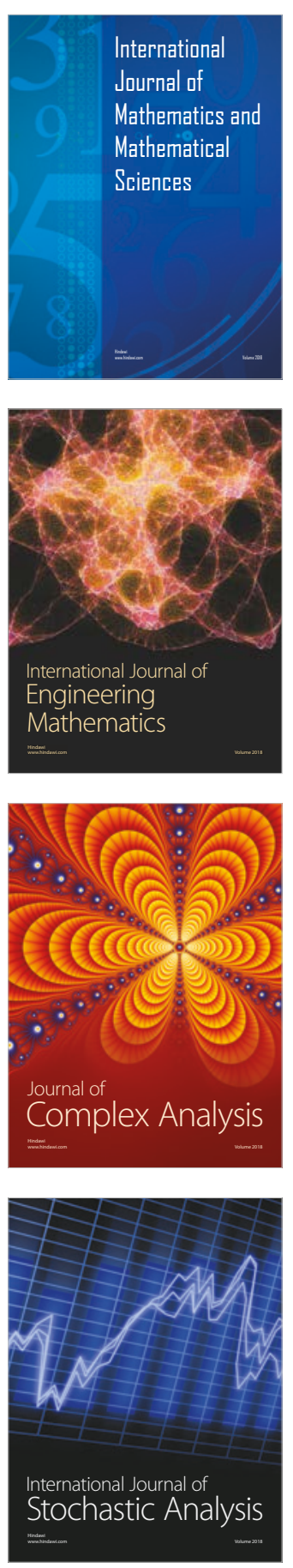
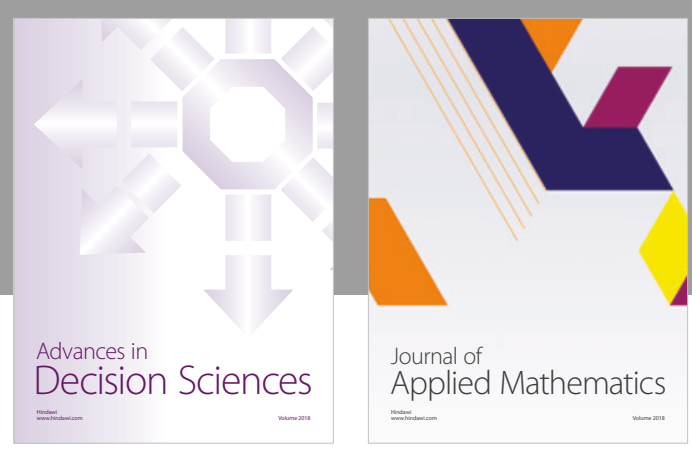

Journal of

Applied Mathematics
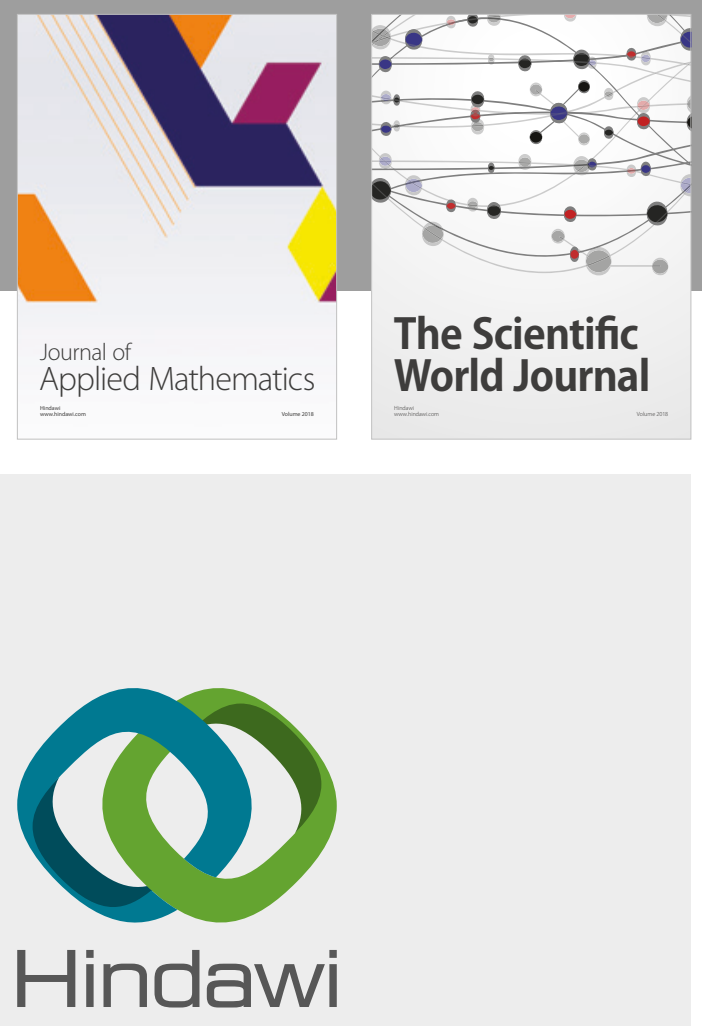

Submit your manuscripts at

www.hindawi.com

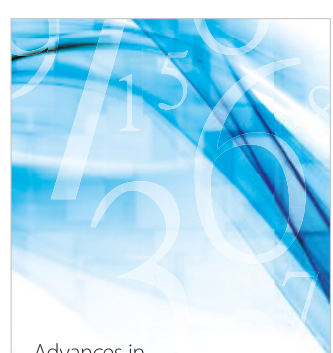

Advances in
Numerical Analysis
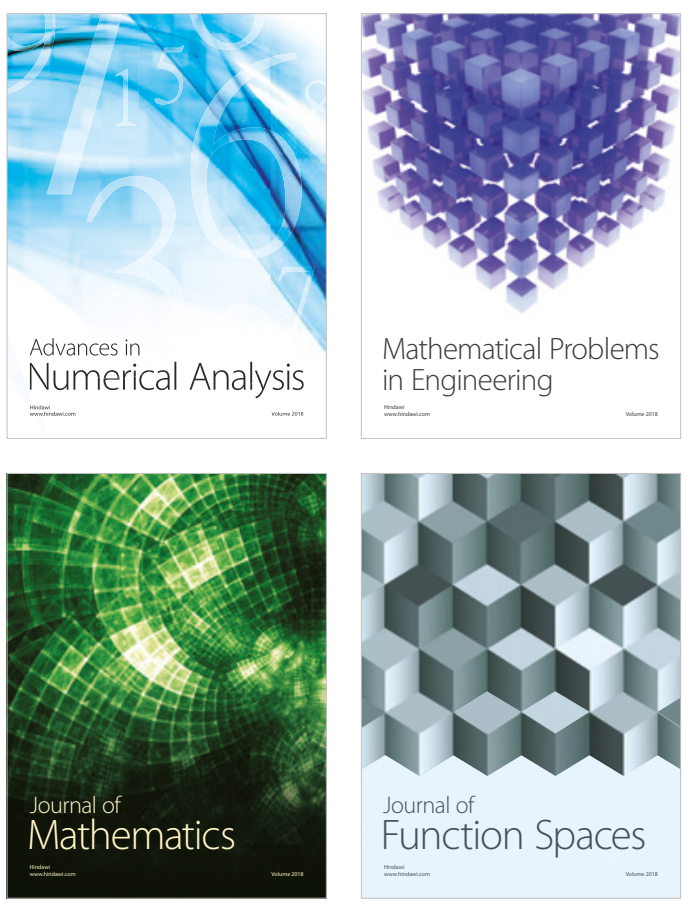

Mathematical Problems in Engineering

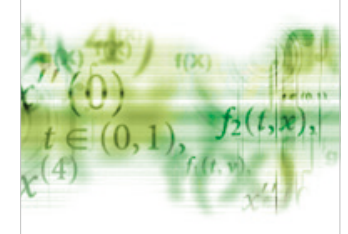

International Journal of

Differential Equations

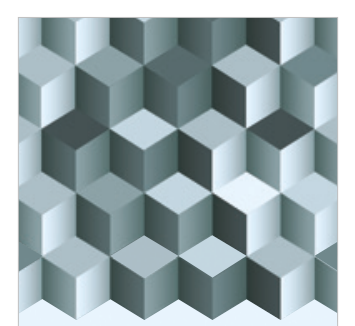

Journal of

Function Spaces
The Scientific

World Journal

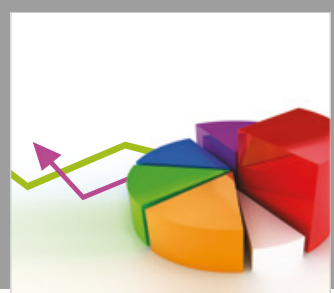

Journal of

Probability and Statistics
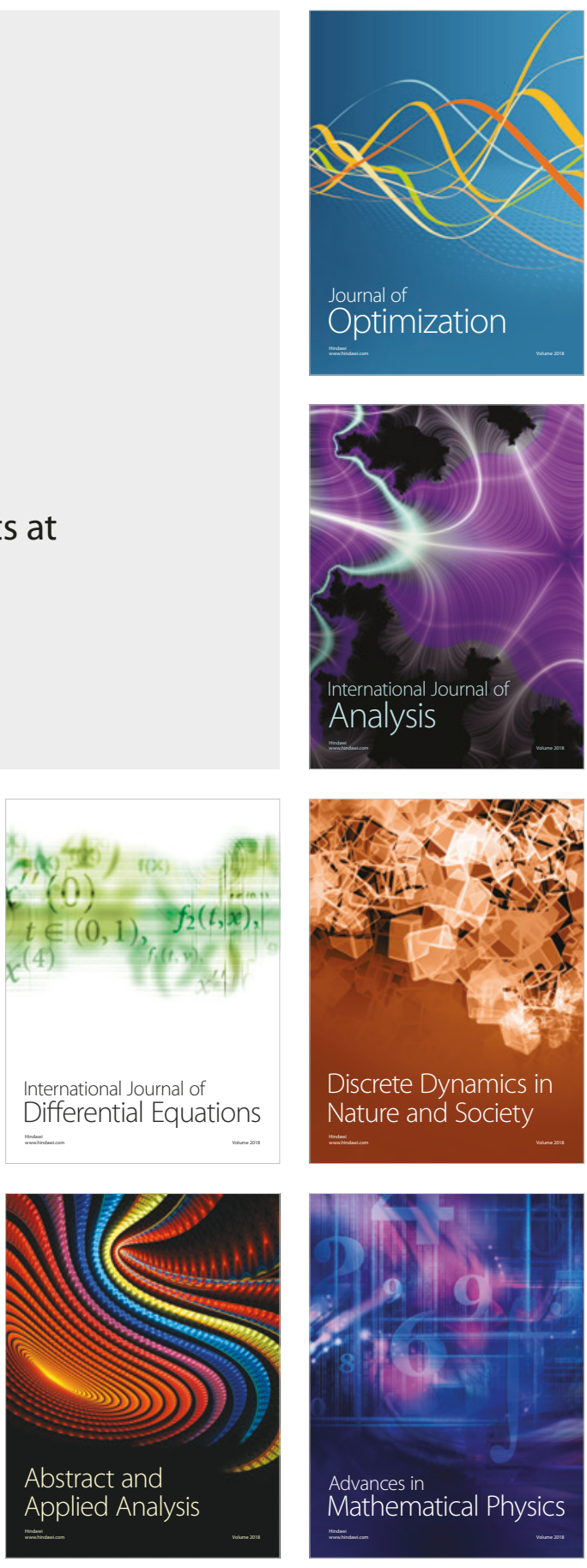